\title{
Training Family Day Care Providers to Work with Special Needs Children
}

Sylvia N. Jones, The Family Day Care Project, and Samuel J. Meisels, The University of Michigan

This paper describes short-term results from a program designed to train family day care providers to work with special needs children. Thirteen providers participated in training sessions and biweekly on-site consultations, and began to mainstream young handicapped children into their family day care homes. Six months after the start of training, the trainees' attitudes towards handicapped children, knowledge about programming for the disabled, and utilization of physical space for enhancing child growth and development were compared to pretraining levels on these measures. Results demonstrated overall significant positive change for the trainees from pre- to posttraining. The paper discusses these findings and their implications.

Family day care is the most frequently used form of child care in the United States. Over 5 million children are currently estimated to be in the care of 1.5 million providers; $70 \%$ of these children are in full-time care (Stentzel, 1985). Although parents, especially working mothers and fathers, are heavily dependent on this type of child care, family day care remains a mostly underground phenomenon-in many states it is unregulated and unlicensed. Operating rules, licensing agencies, and procedures vary greatly from state to state (Adams, 1982), and municipalities often deny providers the right to exist as businesses within residential zones.

Unlike center-based care, family day care typically reflects the personality of an individual provider (usually a woman), rather than a particular theory of child development. Most homes fit into one of three models: (1) extended family; (2) extended family with planned activities; or (3) mini-preschool. In the extended family home, day care children 
are a part of the household routine and are supervised as the provider goes about her daily activities. Toys and equipment are available for children, but the children's interactions, rather than the explicit planning and involvement of the provider, form the core of the day's activities. In the extended family home with planned activities, the provider usually carries out one or more specific projects or field trips with the children each day. These activities are above and beyond the scope of a regular household. Finally, providers who conform to the mini-preschool model are often former teachers whose programs are quite structured. They may follow a particular method of early childhood education and include up to 12 children in their "group homes," rather than the maximum of six children typically found in most family day care situations.

\section{Family Day Care Research}

Despite its popularity, very little replicable, statistically valid research has been conducted on family day care, although several studies have analyzed different characteristics of the models noted above. Wandersman (1981) examined the relationship between numbers of children enrolled and activities in the family day care home. Her results suggest that providers who care for larger numbers (i.e., five to eight) of older preschool children, and who carefully balance age and sex ratios, produce an atmosphere that is more conducive to positive peer interactions. Providers who care for five or more children were also found to have had more relevant educational backgrounds and more extensive experience in day care than those who cared for fewer than five children. Emlen, Donoghue, and Clarkson (1974) also found that providers who chose to work with larger numbers of children had more educational background. These studies suggest that providers with fewer and younger children perceive themselves more as mothers than as professional caregivers, and frequently report experiencing the tensions and role conflicts that are associated with managing a large family.

Howes (1983), too, found that caregivers in day care homes were better facilitators of toddlers' activities when the number of younger children was low, and when the providers worked for fewer hours with reduced housekeeping demands. Howes' findings support Wandersman's (1981) contention that the most successful family day care providers are those who do not adopt the "extended family" model, but who balance the characteristics and numbers of children in the home with the demands of the caregiving environment. 
Wattenberg (1977) has suggested that such providers are more career oriented and more interested in the need for training and professional development. These "modern" providers, who often advocate the "mini-preschool" approach, form the most stable group of family day care providers and are less likely to leave family day care and seek other means of support.

Given the paucity of research on family day care in general it is not surprising that there is very little research about the training of family day care providers. Snow (1982) reported on the differences between training programs for family day care as compared to center-based facilities. Most family day care training focuses on providing support services to providers, increasing their sense of professionalism, and reducing their isolation. In contrast, center-based training programs are geared toward the development of pre- and inservice teachers' knowledge and skills. Nevertheless, in recent years a more professional group of providers has emerged who view themselves as entrepreneurs in the business of delivering quality child care. They maintain careful records on children, keep accounting ledgers, and work with parents on the basis of contracts for services. They attend local and national conferences, enroll in courses, present workshops, and advocate for professional status among early childhood professionals.

This paper reports on a community-based training model designed to increase the professional skills of family day care providers. The model is distinctive in that providers are not only trained to become more professional in their work with young children but are also given specific knowledge, training, and consultation regarding children with special needs. The paper then describes the short-term results of this training program and discusses the preliminary findings of the project.

\section{The Family Day Care Project Training Model}

The Family Day Care Project is a 3-year, federally funded demonstration program, begun in 1984, to train family day care providers in Washtenaw County, Michigan, to care for children with special needs. The project has three goals: (a) to instruct providers about the characteristics of special needs children, (b) to enhance interactions between providers and all of the children in their care, and (c) to increase family day care providers' knowledge about child development, with particular emphasis placed on understanding developmental stages and the relationship of these stages to the planning of appropriate activities 
and caregiving environments for handicapped and nonhandicapped children. The children $(N=27)$ mainstreamed into the homes represent handicapping conditions ranging from mild to severe, including children with cerebral palsy, mental retardation, emotional impairment, spina bifida, visual impairment, and developmental delay. The age of the children ranges from 3 months to 6 years, with a median age at enrollment of 3.3 years. Most of the children also receive special services from local or intermediate school districts.

The project utilizes a range of techniques to achieve its goals, including the following:

- Workshops for family day care providers on caring for children with special needs;

- A resource file on child development and how it is affected by handicapping conditions;

- Visits to family day care homes for continuous support and consultation;

- Medical and educational consultants to work with parents and family day care providers;

- Technical assistance to family day care organizations and family day care providers.

The project has also expanded the existing local information and referral resources for day care providers, parents, and children by developing the following services:

- Referral to trained day care providers for day or respite care;

- Toys and equipment for handicapped children, borrowed from a toylending library;

- A resource center of books, relevant articles, and equipment catalogs.

Each provider who participates in the 1-year training program is expected to take advantage of all of the activities and services noted above. The core of the training program consists of four major elements: (1) a set of 13 half-day sessions at the beginning of the training year that focus on general child development issues and specific concerns related to children with special needs; (2) bi-weekly home visits from the special services coordinator throughout the year, addressing issues of main- 
streaming as well as overall consultation about quality caregiving; (3) inclusion of one to two handicapped children in each provider's home upon completion of the didactic training sessions; and (4) structured and unstructured opportunities for contact with other providers and professionals. Ultimately, the project expects the trainees to be more professional, better caregivers, more committed to family day care, and more capable of providing services to handicapped children and their families.

Another of the major purposes of the project is to reduce the isolation that is so frequently a part of the family day care profession. Isolation can lead not only to personal depression but also to professional burnout. Many providers have commented on how they eagerly look forward to home visits from project staff.

The primary purpose of the home visits is to help providers integrate children with special needs into home activities. The types of special assistance that family day care providers require is dependent on the special needs of the child and the level of experience and expertise of the provider. For example, a child with cerebral palsy required a corner chair so that he could be a part of circle time in the same physical space as the other children, yet at the same time receive optimal trunk support. Another child with a prosthetic leg had trouble keeping pace with the group on riding toys. The project's special services coordinator was able to select a hand-operated Irish mail car for him, not only allowing him to keep pace, but raising his status within the group. A toddler with retrolental fibroplasia was placed with a provider who had no previous experience in working with blind children. Her instinct was to protect the child from being hurt, yet this protection interfered with the girl's gross motor development. In cases like this one, more effective integration was accomplished by identifying problems and solving them through selecting adaptive equipment or special materials, as well as working with the providers to help them better understand the children's needs.

In addition to the home visits, the special services coordinator works with other agency personnel to meet the needs of project families. She maintains on-going contact with the coordinator of the city-funded scholarship program and helps eligible single parent families obtain this support. She also maintains contact with both public and private agencies to ensure that families have access to all the services for which they or their children may qualify. 


\section{Evaluating the Effectiveness of the Training Program}

One of the project's major tasks has been assessment of the effectiveness of the training program. Three related outcomes were studied: attitudes towards handicapped children, knowledge about mainstreaming disabled children, and effective use of space to enhance the development of handicapped and nonhandicapped children. The data currently available regarding these outcomes are from the second of a three-stage research design.

The design corresponds to the 3 years of project funding. The first stage of the design occurred during the project's initial year of operation. Twenty-one providers participated in training while training and evaluation procedures were being piloted. The second phase involves the first wave of formal data collection, obtained from 13 additional providers. The third phase will include longitudinal data collection on the providers who entered the project in its second year as well as data from a third group of trainees. This report will focus on data collected during the first 6 months of the second year of training.

\section{Subjects}

Thirteen self-selected trainees participated in the training and data collection in the second phase of the project. All of the trainees operated their own family day care homes, and all participated in the entire training program. Table 1 presents the demographic characteristics of the sample. Additional data about the trainees are also available: Half of them own their homes; nine are married, three are single, and one is divorced; half of the trainees' spouses work in professional positions; nine of the trainees are white, three are Black, and one is AsianAmerican; one received public assistance during the training period; and one trainee is male.

These demographic characteristics were compared to those reported in a recent survey of the characteristics of center-based staff in the same county (Washtenaw County Association for the Education of Young Children, 1986). On the average, family day care providers were found to be older, to have had less higher education, and to have less experience in child care. These differences are similar to those reported in other demographic reports about family day care home providers (Fosburg, 1981). 
Table 1. Demographic Characteristics of Trainees $(N=13)$

\begin{tabular}{lccl}
\hline \multicolumn{1}{c}{ Variable } & Mean & Range & SD \\
\hline Age (years) & 34.7 & $23-46$ & 6.58 \\
Education (years) & 14.5 & $11-18$ & 2.07 \\
Spouse's education (years) & 13.6 & $9-18$ & 3.8 \\
Number of children & 1.2 & $1-2$ & 0.39 \\
Years registered & 2.0 & $0.5-8$ & 2.08 \\
\hline
\end{tabular}

\section{Measures}

Three outcome measures were utilized on a pre- and posttraining basis to assess the short-term effectiveness of the training program. The measures were selected to assess change in attitudes towards disabled children, knowledge about working with handicapped children, and ability to structure a learning setting - the family day care home-to facilitate child growth and development.

Two of the instruments were either modified by or developed by the project. The first is an assessment of attitudes based on the Classroom Integration Inventory (Haring, Stern, \& Cruickshank, 1958) that was adapted for use in family day care settings. This questionnaire consists of 35 brief descriptions of children with various handicapping conditions, ranging widely in degree of severity. The respondent is asked to select the best setting for the child. The five settings differ in restrictiveness from least restrictive ("Family Day Care Home") to most restrictive ("Special School").

The second questionnaire was developed by the project. It consists of a detailed case study of a 4-year old male ("Jay") with cerebral palsy and some degree of cognitive deficit. Respondents were asked to list specific strategies for (a) adapting the environment to meet the boy's motor needs, (b) using consultants, and (c) fostering a positive relationship between Jay and the other children. Respondents were also asked for their opinion regarding the role of the project in mainstreaming. The questionnaire included both forced choice and openended responses.

Since there is virtually no published research data with which to compare the results of the questionnaires, two panels of nationally recognized experts in the fields of early childhood special education and family day care were asked to respond to both instruments. The results of these panels formed a basis of comparison for the providers' responses. 
The third instrument is the Family Day Care Rating Scale (Harms \& Clifford, 1984). This scale provides an observational rating of the family day care home environment on six dimensions: space and furnishings for care and learning; basic care; language and reasoning; learning activities; social development; and adult needs. The scale consists of 38 items that are rated on a 7 -point scale from 1 (inadequate) to 7 (excellent). Berns (1979) has published preliminary research about the scale.

Homes were rated on a pre- and posttraining basis with an interval of 5 months. Raters were trained by a colleague of the authors of the scale; then two coders rated four of the homes before and after training; one observer rated the other nine homes. Interrater exact agreement averaged .80 for the ratings completed jointly (median rating $=.83$ ).

\section{Results}

The results will be presented in three parts. First, evidence of overall change after training will be presented. Then, the consistency of this change will be analyzed. Finally, associations between change scores and demographic variables will be described.

Evidence of Change. Evidence of trainee change attributable to the project can be seen in a number of ways, although this change differs according to the outcome measure being analyzed. The only measure that did not display significant pre/post differences was the Integration Inventory-the assessment of attitude change.

However, there was a significant change on responses to the case study questionnaire, which assessed knowledge about special needs children. The average change on this measure showed an increase of 5 correct answers, $S D=9, t(12)=2.2, p=.05$. The average number of correct answers at pretraining was $23(S D=11)$; at posttraining, 28 ( $S D$ $=9)$.

There was also a significant improvement on the Day Care Home Rating Scale, $t(12)=2.7, p=.01$. The average change on each item of the scale was $.6(S D=.8)$. The pretraining mean was $3.9(S D=1)$; posttraining was $4.5(S D=.8)$.

In summary, although reliable change was not observed on the attitude scale, both the knowledge and the home rating scales showed significant improvement from pre- to posttraining. Overall, using a multivariate statistic, the average changes were highly significant (Hotelling $T^{2}(3,8)=31.487, p=.008$ ). 
Consistency of Change. In order to determine whether these findings were unduly affected by a small number of trainees who scored particularly well, the data were analyzed for consistency of change. This analysis showed that the number of correct responses to the "Jay" case study increased for 10 of 13 trainees. On the Family Day Care Home Rating Scale 9 of 11 trainees showed average improvement across all scales from pre- to posttraining. The average score of the sample increased on 27 of 35 items on this observational measure. In short, the evidence of change noted in the overall comparisons of pre- and posttraining performance can be identified consistently across items and subjects.

Change and Demographics. Further analyses were conducted to ascertain whether these results were associated with the demographic characteristics of the trainees. No significant relationships were found between change scores and race, spouse's education, marital status, or general experience. However, a trend towards significance $(p=.10)$ was found between age and change on the Home Rating Scale $(r=.59)$. In other words, the older the trainee, the smaller the magnitude of change for that trainee on the rating scale. A significant correlation $(r=.66)$ was observed between change on the knowledge scale and experience with the handicapped $(p<.05)$; the more prior experience a trainee had with handicapped children the greater their change on the case study questionnaire.

Additionally, the correlation between the trainee's formal education and change in attitude, as measured by the Integration Inventory, was significant $(p<.05, r=-.62)$. That is, posttraining deviation from the expert panel group's responses decreased as formal education increased.

An analysis of variance was also conducted to test for the association between change on the home rating scale and amount of contact with other family day care providers. Those with such contact averaged a mean improvement of $1.0(S D=.7)$; those without contact averaged a decrease of $0.1, S D=.4, F(1,10)=6.15, p=.03$.

\section{Discussion and Implications}

This project was designed to implement several broad general objectives: to enhance the professionalism and general knowledge base of family day care providers; to train these providers to effectively 
mainstream handicapped children in their day care homes; and to reduce the personal and professional isolation that is endemic to the family day care provider.

Data were collected from 13 providers who completed the first 6 months of a year of training, including the didactic portion of the training program. The three outcome measures used were designed to assess the impact of the program on trainees' attitudes and knowledge about handicapped children and their ability to arrange their physical environments to be conducive to child growth and development.

Results demonstrated overall significant positive change for the trainees from pre- to posttraining. However, the change was not uniform for all three measures. The questionnaire that assessed attitude change did not show reliable pre/post differences. This is not surprising since attitudes about the disabled are traditionally difficult to modify, and 6 months is a very brief period in which to expect such change. The knowledge and home rating scales did show significant change, and closer examination revealed that these changes were generally consistent across subjects and items. Demographic associations with change scores suggested that higher scores on the outcome measures were related to experience with handicapped children, amount of formal education, and contact with other caregivers. These associations followed an expected pattern suggesting that the more experienced and professional a caregiver, the more effective is the training program.

In short, these results serve as short-term evidence to support the efficacy of the Family Day Care Training Program. However, the data also have some obvious limitations. Chief among them are the small sample size and the brief sampling period. It is possible that different results might be obtained with a larger sample, or with a sample that has different demographic characteristics. Similarly, results might be different if the trainees had been studied for a longer time. An additional limitation is the pre/post methodology; a research design that samples a longer time period would be likely to obtain more sensitive and accurate information.Thus, the results reported here should not be generalized until they have been replicated in the project's final year.

The advantages that accompany the elevation of training and status for the family day care provider would seem obvious, but such change may entail disadvantages as well. Tate (1985) has argued that the "discovery" of family day care presents problems for underpaid Black families whose participation in the workplace depends on the availability of inexpensive, flexible, custodial child care. Her concern is that the emergence of a more highly trained, professional class of day care 
providers will result in more costly services that will be too expensive for the market with the greatest need for them. Other Black child development specialists are concerned that professionalization of day care providers may lead to a "downward extension" of the culture gap that many Black children and families meet as soon as they reach the public school system.

This issue should receive systematic attention, as should several specific questions about the potential effects of mainstreaming handicapped children into family day care homes. These questions include the following: Are children with some types of handicapping conditions more effectively served in family day care than in center-based day care? Is the family day care setting generally more supportive of families with handicapped children than the center-based day care setting? Do disabled children progress at the same rate in family- versus center-based situations? Does mainstreaming in family day care homes entail any negative consequences? Is family day care more cost-effective for families of handicapped children than other forms of care?

The answers to these questions go beyond the data being collected by this project. But the preliminary findings reported in this study provide a basis for beginning to explore more extensively the use of family day care for handicapped children.

\section{Author's Note}

This work was supported by a grant from the Handicapped Children's Early Education Program, Office of Special Education Programs, U.S. Department of Education. We would like to acknowledge the assistance of Ann Saffer and Catherine Schneider, who participated in all aspects of this project, and the invaluable help of Thelma Valenstein who, with the assistance of Margie Wells, Suzanne Borzenweig, and Patricia Kaplan, rated all of the family day care homes, and Lisa Gibson, who helped with data collection. We are also grateful to Tom TenHave for statistical consultation, and to Thelma Harms, Richard Clifford, Donald Bailey, and Debby Cryer for their advice concerning the Family Day Care Home Rating Scale.

\section{References}

Adams, D. (1982). National survey of family day care regulations: Summary of findings. ERIC Document Reproduction No. ED220207

Berns, G.T. (1979). A pilot evaluation to determine the usefulness of the early classroom environmental rating scale to measure change as a result of training. Raleigh, NC: Department of Human Resources, Division of Plans and Operations.

Emlen, A.C., Donoghue, B., \& Clarkson, Q.D. (1974). The stability of the F.D.C. 
arrangement: A longitudinal study. Corvallis: Oregon State University, Continuing Education Publications.

Fosburg, S. (1981). Family day care in the United States: Summary of findings. (Final Report of the National Day Care Home Study). Washington, DC: U.S. Department of Health and Human Services, Office of Human Development Services, Day Care Division.

Haring, N., Stern, G.G., \& Cruickshank, W.M. (1958). Attitudes of educators toward exceptional children. Syracuse, NY: Syracuse University Press.

Harms, T., \& Clifford, R. (1984). Family day care rating scale. Chapel Hill: University of North Carolina, Frank Porter Graham Child Development Center.

Howes, C. (1983). Caregiver behavior in center and family day care. Journal of Applied Developmental Psychology, 4, 99-107.

Snow, C. (1982). Inservice day care training programs: A review and analysis. Child Care Quarterly, 11, 108-121.

Stentzel, C. (1985). Child care fact sheet. Washington, DC: National Commission on Working Women.

Tate, C. (1985). Family day care: Implications for the black community. Prepared for the 15th Annual Conference, National Black Child Development Institute, Inc., Washington, DC.

Wandersman, L. (1981). Ecological relationships in family day care. Child Care Quarterly, 10, 89-102.

Washtenaw County Association for the Education of Young Children. (1986). Cbild care staff working conditions project. Ann Arbor, MI: Author.

Wattenberg, E. (1977). Characteristics of family day care providers: Implications for training. Child Welfare, 56, 211-230. 